\title{
Deadly Automatic Systems: Ethical And Legal Problems
}

\author{
Mamychev Alexey Yurievich ${ }^{1}$, Gayvoronskaya Yana Vladimitovna ${ }^{2}$, Petrova Daria Anatolievna ${ }^{2} \&$ \\ Miroshnichenko Olga Igorevna ${ }^{2}$ \\ ${ }^{1}$ Department of Legal Foundations of Administration, Moscow State Institute of International Relations, \\ Moscow, Russia \\ ${ }^{2}$ Department of Theory and History of State and Law, FEFU School of Law, Vladivostok, Russia \\ Correspondence: Mamychev Alexey Yurievich, Professor of the Department of Theory and History of Russian \\ and Foreign Law, Vladivostok State University of Economics and Service, Vladivostok, Russia. E-mail: \\ mamychev@yandex.ru
}

Received: October 21, 2019

Accepted: November 18, 2019 Online Published: November 28, 2019

doi:10.5539/jpl.v12n4p50

URL: https://doi.org/10.5539/jpl.v12n4p50

The study was carried out with the financial support of the Russian Foundation for Basic Research in the framework of research project No. 19-011-31031

\begin{abstract}
Artificial intelligence, neural networks, speech and behavior recognition systems, drones, autonomous robotic systems - all of these and many other technologies are widely used by the military to create a new type of lethal weapon programmed to independently decide to use military force. According to experts, production of such weapons will be a revolution in military affairs, the same kind of revolution that the creation of nuclear weapons made back in the days.

Adoption of fully autonomous combat systems raises a number of ethical and legal issues, the major of which is a destruction of a supposed enemy's manpower by a robot without a human command. This article focuses on the legal aspects of creating autonomous combat systems, their legal status and the prospects of creating an international document prohibiting lethal robotic technologies.

As the result of the study, the authors came to a conclusion that there is no direct legal restriction on the use of fully autonomous combat systems, however, the use of such weapons contradicts the doctrinal norms of international law. The authors also believe that a comprehensive ban on the development, use and distribution of robotic technologies is hardly possible in the foreseeable future. The most possible scenario for solving the problem at an international level is only a ban on the use of this type of military equipment directly during an operational activity of an armed conflict. At the same time, the authors consider it necessary to outline the acceptable areas of application of robotic technologies: medical and logistical support of military operations, military construction, the use of mine clearing robots and similar humanistically justified measures.
\end{abstract}

Keywords: autonomous combat robots, international humanitarian law, deadly autonomous systems, robots, killer robots

\section{Introduction}

Military leaders of any state always seek to minimize losses among the personnel of their troops. Digitalization comes to the aid of the military by changing methods and means of controlling combat operations and increases the efficiency, safety and effectiveness of combat units. Different factors speak well for weapons equipped with AI: economic, military-tactical, and organizational.

From the point of view of humanitarian law, AI in the military field can solve humanistic problems, saving living soldiers from their actual participation in combat operations. Economic efficiency and lowering costs of maintaining military complex are sufficient reasons that explain impossibility of modern states to abandon the widespread use of digital technology and AI in military affairs. The development of AI technologies leads to an increasing autonomy of devices, up to full automation, which does not require human control. At the moment, technology has come close to creating fully autonomous deadly systems (ADS) - weapon systems of the future that will be able to work without significant human control by the aid of sensors and AI (Warham, 2016). 
According to experts, at their current state of recognition and reaction systems robots are still very far from ordinary soldiers who can speed-assemble automatic rifles. Experts point to a lot of unsolved technical problems which today do not allow us to talk about the complete autonomy, speed, survivability, accuracy and safety of existing combat robots (Bugakov, I.A. \& Tsarkov, A.N., 2017). But this is precisely the case when humanity needs to solve the problem before reaching the point of no return.

\section{Research Methodology}

Purpose of the present work is to identify and formulate ethical and legal problems with the use of ADS which require international legal regulations. To achieve this goal, the authors set the following tasks: to describe main ethical dilemmas in the development and use of ADS; to give an idea of the international legal regulations of the processes of development and use of ADS; to give an idea of scientific discussion on ethics of the use of ADS; to propose a viable regulatory model of the development and use of ADS which will be able to solve the identified ethical problems.

The study was carried out from the perspective of axiological and humanistic approaches which involve consideration of human life, rights and freedom as a self-sufficient value that determines attitude to the other phenomena and processes in society and nature. The study of technological progress from the perspective of an axiological and humanistic approach is the main methodological installation of the humanities. In the framework of these approaches, the authors used various methods and logical techniques for processing information. The main method of the work is analysis. Conclusions were based on the methods of historical analysis, comparative legal analysis, structural and functional analysis, formal legal analysis (regarding the interpretation of documents). Also, the authors used methods of scientific review and expert assessment, which allow to introduce the reader to the problem and characterize the existing regulation of relations using ADS.

\section{Main Part}

Despite the fact that fully autonomous combat robots have not yet been developed, prototypes of such weapons have long been used in many countries of the world. Peacekeeping public organization "Pax" (Peace) (Pax, 2018) names at least 4 examples of real-life models of weapons that can work on land, under water and in the air in an autonomous mode without direct human control:

- Ground-based stationary robot SGR-A1 is equipped with a grenade launcher and an automatic rifle. It was designed by a South Korean company to control the border with North Korea. Due to infrared sensors and a motion recognition program, the robot can track intruders and open fire on them both in automatic mode and in controlled one.

- Israeli invention "Harpy" is a rocket to be launched from a ground vehicle. It automatically detects, attacks and destroys enemy radar emitters. Also, it can spend up to 9 hours in the air in search of a target.

- American autonomous submarine «Sea Hunter» is designed to track enemy submarines and can work without contacting the operator for 2-3 months. No weapons are currently installed on this sample.

- Being designed in France, pilotless stealth plane «Nero» can be autonomous for more than 3 hours and is aimed to detect and snoop ground targets. It can independently set goals and automatically attack.

Pax Researchers are convinced that similar technologies will help to create combat killer robots in years ahead, not in decades as was previously thought.

Also, armed drones, pilotless planes, combat stationary guard robots, automatic combat complexes barging ammunition and other weapons are considered to be the "precursors" of fully autonomous weapons. In the decision-making cycle of such weapons there is still a person who can control the process of target selection and decision-making on the use of the force.

An example of modern development level of military technologies based on AI is Alpha artificial intelligence system developed by Psibernetix (founded by graduates of the University of Cincinnati, USA). Alpha won a simulated air combat on a simulator created by military expert, retired Air Force Colonel Gene Lee, who has been training military pilots as an expert and has been testing such systems for over 30 years. The expert never managed to hit a computer opponent and failed to leave. Alpha was tested by other military pilots who were also defeated. In the future, developers plan to train Alpha on other military pilots after which they expect to use artificial intelligence to control a real aircraft (Vorontsov, 2016).

It's that obvious that with the development of the technologies the idea of war and the participation of soldiers in it is changing, leaving many complex moral, ethical, philosophical and legal questions without unambiguous answers. The major issue from this set is ethical - a fully autonomous weapon will not have a human ability to 
empathize, which can act as a key in deciding whether to commit a murder (Warham, 2016). Man gives way on a control over the decision on who will live and who will die to an inanimate machine. The machine is not capable of realizing neither the value of human life nor the significance of its loss ( Warham, 2016).

The developers of lethal technologies were the first to deal with moral and ethical-philosophical dilemmas. Having made a choice for themselves, some researchers of artificial intelligence in an open letter stated that they were not interested in creating weapons based on AI. As previously, most chemists and biologists were not previously interested in creating nuclear and chemical weapons (Open letter from AI researchers, 2015). The letter caused a wide public outcry and due to the initiative of scientists and public organizations a campaign to prevent the prohibition of combat robots began in 2013. Currently, discussions on the prohibition of the development and use of automated combat systems are being held in the United Nations.

Non-governmental organizations such as Stop Killer Robots, Article 36, the International Committee for Robot Arms Control, as well as well-known scientists and businessmen (S. Hawking, I. Mask, and S Wozniak) believe that fully autonomous weapons will not be able to comply with international humanitarian law and human rights, they will also create a problem with defining the responsible executives in case of illegal actions of autonomous devices Vyitlovatykh, 2019).

The haste and rashness of military developments of AI can lead to a new arms race in the world and to a gradual disregard of the norms and principles of international law (Vyitlovatykh, 2019).

From a legal point of view, the requirements of international humanitarian law should be applied to all types of weapons including weapons based on AI systems. International law does not contain a direct rule prohibiting the use of fully automatic combat systems, therefore, discussions about the validity of using this type of weapon are being conducted in terms of compliance with the doctrinal norms of humanitarian law. Supporters of the ban on the production of deadly technology firstly cite the clause of the Russian lawyer F.F. Martens. In a 1996 (Applicable international law. Anthology, 2012) advisory opinion on the legitimacy of the threat or use of nuclear weapons, the UN International Court of Justice recognizes this clause as a source of customary international law and cites its modern version, as enshrined in clause 2 of section 1 of Additional Protocol 1 to the Geneva Conventions on August 12, 1949 concerning the protection of victims of international armed conflicts:

«In cases not provided by this Protocol or other international agreements, civilians and combatants shall remain under the protection and operation of the principles of international law stemming from established customs, from the principles of humanity and from the requirements of public consciousness» (Additional Protocol to the Geneva Conventions of 12 August 1949 Relating to the Protection of Victims of International Armed Conflicts (Protocol I) (August 12, 1949) Retrieved from International Committee of the Red Cross https://www.icrc.org/ru/doc/assets/files/2013/ap_i_rus.pdf2. Thus, the Martens clause calls for addressing the principles of humanity in any unresolved situation affecting people's lives.

From the same conclusion the Court deduced a fundamental universal principle applicable for all types of weapons, not only for nuclear weapons: the state's will to use weapons is not unlimited. The Court bases two rules on this principle. The first rule - the distinction rule - is that civilians should not be targeted and weapons that are unable to distinguish combatants from non-combatants should be prohibited. Also, weapons that cause unnecessary suffering and cause more damage than required by the achievement of military goals should be banned - this is the rule of proportionality (Additional Protocol to the Geneva Conventions of 12 August 1949 Relating to the Protection of Victims of International Armed Conflicts (Protocol I) (August 12, 1949) Retrieved from International Committee of the Red Cross https://www.icrc.org/ru/doc/assets/files/2013/ap_i_rus.pdf).

Autonomous lethal technologies in their current form do not correspond to the first rule - the rule of distinction. So, automatic algorithm is not able to distinguish a civilian from a military, if the first one is holding a weapon in their hands or in case if civilians are taken hostage and used as human shields. It is suggested that autonomous combat systems could pass the distinction test. So, if a robot algorithm obtains a program that allows to hit the target only after a shot or attack by a potential enemy (Sychev, 2018). In our opinion, this proposal does not solve the problems mentioned above, because it does not exclude the possibility of error and allows the death of civilians as the result of this error.

A discussion arose regarding a compliance of autonomous robots with the second rule. Supporters of the prohibition of robotic lethal technologies understand the correlation between harming civilians and gaining a military advantage as the principle of proportionality (Human rights watch, 2016). Researcher from the Amsterdam Center of International Law, Jerome Van de Bugard, insists that this interpretation is one-sided, 
since it applies only to the civilian population (Jeroen van den Boogaard, 2015). According to the researcher, the right to life of soldiers must be included in this concept. Otherwise, a conflict arises between the right of civilians and soldiers to live with a priority being given to the first ones. The use of robots does not cause suffering to military personnel, therefore, autonomous robotic systems comply with the rule of proportionality. Regarding the question of the appropriateness of equalizing the rights of civilians and soldiers, the researcher says that the beginning of a military operation is regulated in detail and balanced in terms of the rule of proportionality before mobilization.

In our opinion, this position opens up wide opportunities for the legitimation of military actions in the territory of another country. The opinion of a Dutch researcher describes an ideal theoretical vacuum in which all international conflicts go not only within the framework of humanitarian law, but also fully comply with moral standards. For example, sending of US troops to Vietnam or Afghanistan, perhaps, was calculated from the point of view of the principle of proportionality, but the goal of the invasion did not pursue humanistic goals at all. Losses among the civilian population in these conflicts were extremely high, and if at that time there would have been automatic combat robots in service, then there would be no one to experience the pangs of conscience.

It should be noted that the study of the Amsterdam Center takes into account only state actors, while states have not been considered the only participants in international processes for a long time. Thus, on September 14, 2019, an attack of 10 drones against the largest oil refinery in Saudi Arabia took place (CNN (USA): attack on oil facilities in Saudi Arabia changed the course of the confrontation in Persian Gulf Retrieved from Inosmi.ru https://inosmi.ru/economic/20190916/245829335.html). Hussite rebels claimed responsibility. And in this case, is it necessary to equate the rights of the rebel army with the rights of the workers of the plant? It sounds ridiculous.

Despite the fact that the current norms of international humanitarian law rather prohibit the use of those types of weapons that do not comply with the principles of distinction and proportionality, humanitarian law in no way restricts the right of states to create such types of weapons. This opportunity is used by China that joined the ban on the use of autonomous deadly technologies, but did not abandon their development.

«Pax» investigated the role of IT companies in the development of autonomous deadly robots (Pax, 2019). The result of the study shows that almost all well-known giant companies are involved in the development of technologies that can be a part of deadly software algorithms. Pax ranks 50 IT companies in terms of their involvement in the production of killer robots.

The first group includes companies directly involved in the creation of autonomous combat robots. The report featured 22 companies specialized in various aspects of the work of robots. For example, among such companies there are Microsoft, Clarifai and Amazon which are responsible for face and speech recognition algorithms; Anduril Industries - for introduction of artificial intelligence platforms. Almost all companies from the first group entered into contracts with the defense ministries of their countries for participation in military projects.

The second group of companies is developing technologies for the military or defense complex, however, company management announced that their companies were not involved in the development of killer robots. Thus, Facebook, Alibaba and IBM are working on technologies for recognizing patterns of behavior, recognition of faces and speech, programming chips for artificial intelligence. Apart from management statements, companies from the second group do not confirm their involvement in the production of deadly technology.

The third group includes companies involved in the development of AI technologies, such as facial recognition and speech recognition algorithms, visual perception, and creation of robotic technology, but for ethical reasons, employees of these companies refused to participate in the development of deadly robots. Among such companies are the IT giant Google (Campaign to stop killer robots, 2019) which ceased its participation in the American military project Maven in 2018 due to the refusal of specialists to turn their achievements into weapons; Israeli companies General Robotic and Arbe robotics; Japanese Softbank; Russian VisionLabs. All these companies have named ways to protect their intellectual work from being used by the military to create autonomous combat robots.

The idea of introducing a ban on the use, development and distribution of robotic lethal technologies has been discussed at the regional and international level since 2013. Negotiations have not brought tangible progress for six years, adopted international resolutions only emphasize the importance of an interstate dialogue on the prohibition of fully autonomous deadly machines. Such declarations, for example, include the resolution of the Organization for Security and Cooperation in Europe of July 2019 (OSCE Parliament, 2019) - a non-binding document that once again calls for a discussion of the problem. 
Obviously, the problem under consideration has taken a political turn: robotic technology is a profitable investment to achieve a military advantage. A political compromise is needed to really reach an agreement. Thus, the 1968 Agreement on the Non-Proliferation of Nuclear Weapons (NPNW) is a compromise between nuclear and non-nuclear countries in which a legal circle is drawn from five countries (Russia, the USA, France, China, and Great Britain) that possess nuclear weapons. And the five nuclear countries, in turn, undertake not to use nuclear weapons against non-nuclear states. However, the application of such a compromise model to the case of non-proliferation of robotic lethal technologies is the least advantageous option for non-nuclear states, since, in addition to the legal possession of nuclear weapons, the same group of countries will gain exclusive ownership of another type of most destructive weapons. Then non-nuclear countries will also become non-technological, and their dependence on strong countries will increase.

\section{Conclusion}

The most likely scenario for concluding an international agreement on the ADS problem, as we see it, is not a comprehensive ban on the development, use and distribution of robotic technologies without significant human control, but only a ban on the use of this type of military equipment. With such a development of events, one can only be glad for our planet. But as we have already noted, taking into account political and economic interests in the modern world stage, the likelihood of a quick and painless adoption of such a compromise document is not high. In a meaningful way, the regulation of ARS should provide acceptable areas of use of devices with AI systems and autonomous devices. These areas should include medical and logistical support of military operations, military construction, the use of mine clearing robots and similar humanistically justified measures.

Thus, among the acceptable areas of robotics and AI in the military field, one can recognize the following areas of AI development noted by scientists:

- intellectual support of the actions of downstream troop units (military personnel will be provided with the intelligence-driven operations, information on assessing the situation, ensuring interaction, coordination and subordination);

- medical support in the field of military affairs (android robots for medical evacuation; AI methods for making a diagnosis; robotic doctors for resuscitation, conservative and surgical treatment of servicemen who received injuries; accelerated production of medicines taking into account the condition of the affected person, etc.);

- assessment of the state of military personnel in everyday and combat activities (intelligent algorithms for recognizing and evaluating a person's functional and depressive states by speech, posture, head and eye position, etc.);

- creation of bio-cybernetic operator's booths to improve the ergonomic characteristics of the AMSE [armament, military and special equipment] (military life support systems, intellectual and psycho-physiological support systems that are reconfigurable in accordance with the combat tasks and individual characteristics of the operators and their current functional state);

- creation of intelligent simulators for training operators, drivers, and pilots on the basics of AMSE control in a difficult environment;

- wise intelligence technologies (deciphering intelligence, processing information from cyber-intelligence);

- information warfares (using AI to collect and analyze secret service information, preparing information impacts, fake news, press releases, cyber attacks, etc.).

Scientific ethics can help to achieve positive results in terms of the correlation of technological progress and the principles of international humanitarian law. Perhaps researchers of artificial intelligence will adopt a kind of code of the researcher, due to which it will become impossible to use robotic technology as a weapon. There still remains a hope that moral responsibility of those directly involved in the development of technologies will be able to stop the process of creating deadly robots from the inside.

\section{References}

Additional Protocol to the Geneva Conventions of 12 August 1949 Relating to the Protection of Victims of International Armed Conflicts (Protocol I). (1949, August 12). Retrieved from https://www.icrc.org/ru/doc/assets/files/2013/ap_i_rus.pdf

Applicable international law. Anthology. (2012). Bishkek, «Altyn Print» Co., Ltd. Pp.518-519.

Autonomous weapons: an open letter from AI researchers (artificial intelligence) and robots. The future of life institute. Retrieved from https://futureoflife.org/open-letter-autonomous-weapons/ 
Bugakov, I. A., \& Tsarkov, A. N. (2017). Bulletin of the Institute of Engineering Physics Intellectualization of military robotics: terminological and technological problems

CNN (USA): attack on oil facilities in Saudi Arabia changed the course of the confrontation in Persian Gulf. Retrieved from https://inosmi.ru/economic/20190916/245829335.html

Do killer robots exist? In Pax. Retrieved from https://www.paxforpeace.nl/media/files/pax-booklet-killer-robots-what-are-they-and-what-are-the-concerns. pdf

Don't be evil? Retrieved from https://www.paxforpeace.nl/publications/all-publications/dont-be-evil

Luxembourg declaration and resolutions adopted by the OSCE Parliamentary Assembly at the twenty-eighth annual session. Retrieved from https://www.oscepa.org/documents/annual-sessions/2019-luxembourg/3882-luxembourg-declaration-eng/fil e

Making the case The Dangers of Killer Robots and the Need for a Preemptive Ban. Retrieved from https://www.hrw.org/sites/default/files/report_pdf/arms1216_web.pdf

Rise of the tech workers. Campaign to stop killer robots. Retrieved from https://www.stopkillerrobots.org/2019/01/rise-of-the-tech-workers/

Sychev, V. (n.d.). Someone has to fight. Retrieved from https://nplus1.ru/material/2018/09/05/war-robots-laws

Vorontsov, N. (2016). Artificial Intelligence Surpasses Military Pilots. Retrieved from https://nplus1.ru/news/2016/06/29/Daisy-Bell

Vyitlovatykh, A. V. (2019). Artificial intelligence as a factor in the military policy of the future Problems of National Strategy.

Warham, M. (2016). Speech at the round table Combat robots: threats taken into account or unforeseen? International conference of the PIR Center and the Diplomatic Academy of the Russian Ministry of Foreign Affairs Agenda of the $21^{\text {st }}$ century - new technologies and challenges to global security. Security Index, $22(3-4), 118-119$.

\section{Copyrights}

Copyright for this article is retained by the author(s), with first publication rights granted to the journal.

This is an open-access article distributed under the terms and conditions of the Creative Commons Attribution license (http://creativecommons.org/licenses/by/4.0/). 